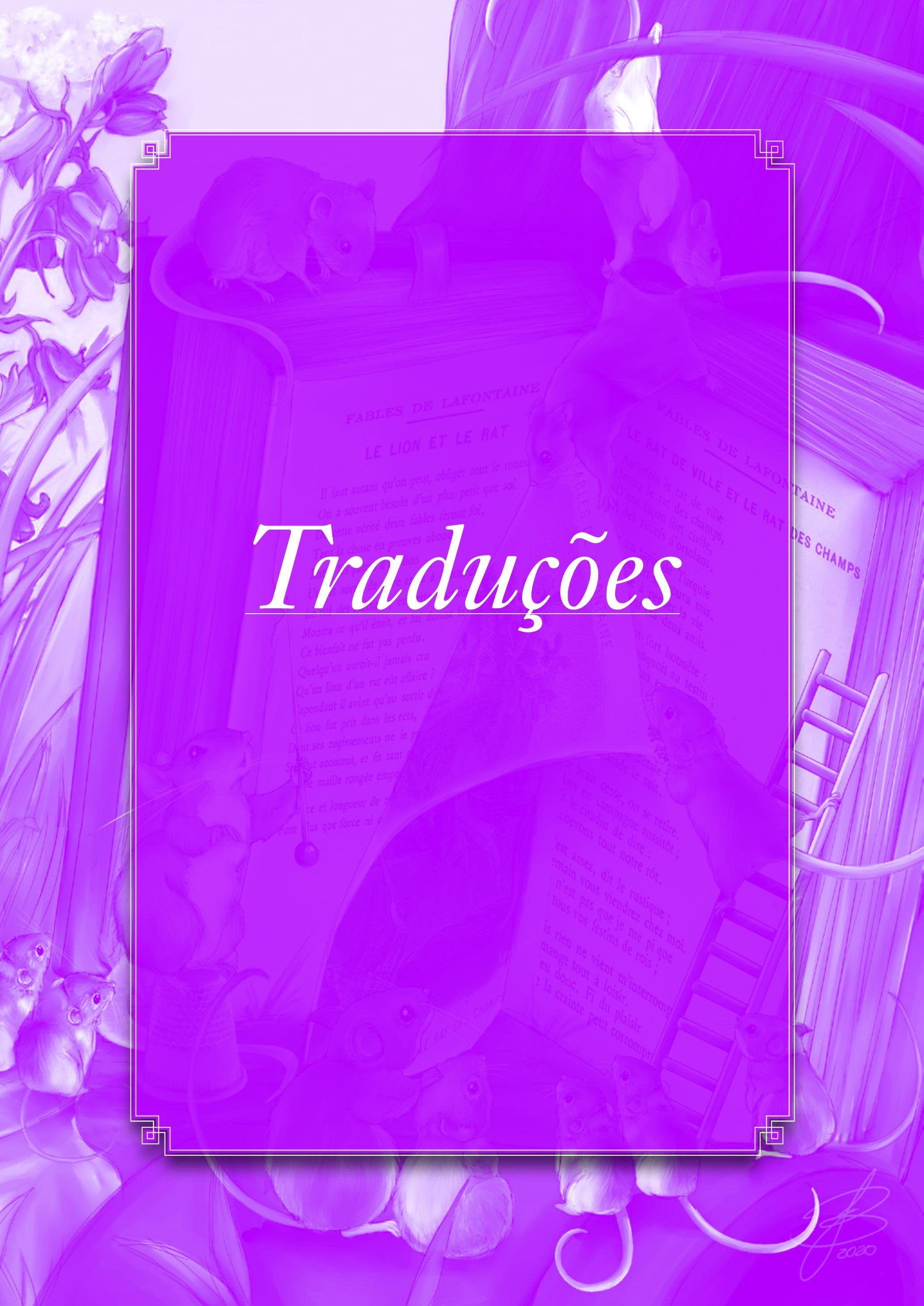




\section{O paradoxo de Charles Perrault: como contos de fadas aristocráticos se tornaram sinônimo de conservação folclórica}

Charles Perrault's paradox: How aristocratic fairy tales became synonymous with folklore conservation

\section{$\underline{\underline{\text { Lydie Jean }^{\mathrm{I}}}}$}

Tradução por Paulo César Ribeiro Filho

1 Mestra em Literatura Francesa Moderna pela Universidade de Paris IV Sorbonne. E-mail: lydiejean@gmail.com. 2 Doutorando em Literatura Infantil e Juvenil pela Faculdade de Filosofia, Letras e Ciências Humanas da Universidade de São Paulo. 
RESUMO: No final do século XVII, Charles Perrault escreveu aquele que viria a ser o seu mais célebre livro e um dos maiores sucessos da literatura francesa: as Histórias e Contos do Tempo Passado. Costuma-se pensar que Perrault reuniu a matéria de seu livro diretamente do folclore tradicional, a fim de preservar o seu panteão. No entanto, estudos mostram que, mesmo se ele estivesse inspirado pelos contos populares, não estava interessado em sua conservação. Contudo, a popularidade dos contos de fadas de Perrault foi tamanha que eles acabaram retornando ao folclore, tornaram-se parte importante da tradição popular e até ajudaram a preservá-la. Esse processo pode ser explicado por causas sucessivas, que, juntas, tornaram esse movimento possível. Desde o início, os contos de fadas de Perrault foram modificados para caber em publicações baratas. Quando o estudo do folclore entrou em voga, seus contos foram analisados por uma perspectiva errônea. E quando estudos mais sérios começaram a ser feitos, já era tarde demais: não se podia mais dizer quais contos eram contos originalmente populares e quais eram as versões modificadas de Perrault.

PALAVRAS-CHAVE: Charles Perrault; Contos de fadas; Folclore; Préciosité; Tradição popular; Literatura.

ABSTRACT: At the end of the 17th century, Charles Perrault wrote what would remain his most famous book, and one of the biggest successes of French literature: the Histoires et Contes du temps passé. It is commonly thought that Perrault took the matter of his book directly from traditional folklore, in order to preserve its tales. However, studies show that even if he was inspired by folktales, he was not interested in their conservation. But the popularity of Perrault's fairy tales has been so extensive that they finally returned to folklore, became an important part of it and finally helped to preserve it. This process can be explained by successive causes, which all together made it possible. From the very beginning, Perrault's fairy tales were modified to fit cheap publications. When it became a fashion to study folklore, his tales were analyzed from a wrong angle. And when more serious studies were made, it was too late: one could no longer tell which tales were original folktales, and which were Perrault's modified versions.

KEYWORDS: Charles Perrault; Fairy tales; Folklore; Préciosité; Popular tradition; Literature. 


\section{Apresentação}

Em um estudo intitulado O paradoxo de Charles Perrault: como contos de fadas aristocráticos se tornaram sinônimo de conservação folclórica, a pesquisadora Lydie Jean averigua os excessos da etnografia romântica tendo por base algumas evidências que saltam aos olhos dos leitores mais experientes que se dedicam à leitura da coletânea Kinder- und Hausmärchen (“Contos Infantis e Domésticos”), dos escritores e acadêmicos alemães Jacob e Wilhelm Grimm. Acontece que, na segunda metade do século XVIII, os dois filólogos e bibliotecários reuniram e publicaram uma série de "narrativas folclóricas e contos populares" sob o ideal romântico de que uma verdadeira identidade nacional residiria nas tradições do povo simples, em suas histórias e crenças. A autora, porém, postula que, ainda que as publicações dos Grimm supostamente buscassem a expressão da mais original cultura tradicional alemã, em suas antologias foram incluídas tramas narrativas já presentes em algumas das aventuras que constam no clássico francês Histórias ou Contos do Tempo Passado com Moralidades, Contos da Mamãe Gansa, de Charles Perrault, pioneiro no estabelecimento do chamado "horizonte de expectativas" temáticas e estruturais do conto de fadas, título publicado em Paris, em 1697, dirigido sobretudo aos leitores da alta aristocracia francesa. Esse estudo provocador nos instiga e nos convida a refletir acerca de um certo processo de "retroalimentação literária" no tocante à influência que a narrativa oral exerce sobre o texto escrito e vice-versa, ressaltando a ideia de que a zona fronteiriça entre o oral e o escrito é envolta em névoa. Ademais, alguns dos temas trabalhados panoramicamente no texto de Lydie Jean constam nas elucubrações apuradas de Ruth Bottigheimer, na entrevista presente nesta edição da Revista Literartes.

Paulo César Ribeiro Filho 


\section{Introdução}

A primeira imagem que geralmente vem à mente quando Charles Perrault é mencionado é a de um velho gentil ouvindo uma aia, contando às crianças maravilhosos contos de fadas. Esse agradável Sr. Perrault supostamente teria coletado esses contos de fadas com o intuito de entreter seus próprios filhos e, eventualmente, salvar essas histórias do esquecimento. Tal ideia comumente difundida será chamada de "o mito do bom Sr. Perrault" neste artigo. Esse mito baseia-se na ideia de que Perrault escreveu suas Histórias e Contos do Tempo Passado, também chamadas de Contos da Mamãe Ganso, com a genuína intenção de prestar reverência ao folclore tradicional. Perrault escreveu doze contos no total: A Paciência de Grisélidis, Os Desejos Ridículos, Pele de Asno, estas três escritas em verso; A Chapeuzinho Vermelho, A Bela Adormecida no Bosque, $\mathrm{O}$ Gato de Botas, Cinderela, Barba Azul, O Pequeno Polegar, As Fadas e Riquete de Topete, estes escritos em prosa e com uma moral ao final. Quase todos os contos mencionados têm, de fato, origem no folclore tradicional, mas foram sensivelmente modificados por Perrault para se adequar ao público-alvo pretendido: a aristocracia.

Pensar que Perrault estava interessado na cultura popular seria um erro. Essa crença generalizada pode ser explicada pelo fato de que seus contos se tornaram parte da tradição popular. Perrault modificou os contos tradicionais com o intuito de entreter um público aristocrático, mas seu próprio trabalho também foi modificado. A cultura popular reapropriou-se de seus contos, mas o nome de Perrault permaneceu inseparável das histórias. Esse processo de reescritura das histórias tradicionais por Perrault e a sua futura reatribuição à cultura popular é o que este artigo tentará analisar. 


\section{Contos de fadas aristocráticos}

\section{I. A moda da préciosité}

Os contos de fadas de Perrault foram escritos entre 1694 e 1697, numa época em que a préciosité estava na moda na França e em toda a Europa. Préciosité, ou preciosidade, era uma tendência aristocrática. Os denominados "preciosos" acreditavam que os diálogos brilhantes, as provas de inteligência e a elegância linguística eram meios de se denotar sua distinção. O humor requintado e o pensamento crítico de seus escritos expressavam um estilo de vida. $\mathrm{O}$ contexto de refinamento em que viviam condicionava suas obras, de sorte que consideravam o modo de vida burguês como o auge da vulgaridade.

Como um gênero literário menor, proveniente da cultura popular e constituído principalmente de formulações simples, o conto teria sido desprezado pelos preciosos. No entanto, era o que estava em voga nos salões literários e, naquela época, todos que buscavam algum reconhecimento literário escreviam contos (STORER, 1928). Eram versões estruturalmente elaboradas de histórias que realmente não se pareciam com contos populares. E mesmo que os contos tradicionais muitas vezes inspirassem os contos de fadas preciosos, os escritores modificavam as versões originais a fim de que não fossem prontamente reconhecidas. Os contos de fadas escritos nos salões costumavam ser longos e de estilo elaborado; ocorre também que muitos deles eram totalmente inventados, não tinham raízes populares e não respeitavam nenhuma das características típicas dos contos tradicionais. Esses contos veicularam preceitos de uma subcultura libertina, partilhada entre pessoas cultas: não há nada de ingênuo ou inocente aqui.

O conto de fadas precioso foi projetado para o entretenimento da aristocracia e não tem quase nada de semelhante com o conto de fadas popular do qual ele se origina. É preciso entender que os contos de Perrault definitivamente pertencem à préciosité (ROBERT, 1982). Algumas das morais que encerram os contos e alguns detalhes nos textos são, obviamente, comentários espirituosos dirigidos a pessoas instruídas. Esses 
detalhes não podem ter sido extraídos de contos populares e muito menos de contos infantis. No entanto, como veremos mais adiante, Perrault manteve muitos aspectos dos contos tradicionais. A mistura de preciosidade e tradição forneceu ao seu trabalho um polimorfismo único que provavelmente é a razão de seu sucesso.

\subsection{Quem é Perrault?}

Charles Perrault nasceu em 1628, em uma rica família burguesa que havia alçado à corte real. Junto de seus sete irmãos e irmãs, foram criados pelos pais no "ódio às superstições populares", um contexto típico do racionalismo iluminista da época. Suas primeiras obras, escritas com seus irmãos, refletiam as contradições da classe burguesa: aliada às classes baixas, mas aterrorizada com a possibilidade desse aliado ficar fora de controle. Eles zombavam das massas e de seu linguajar não refinado: se usavam seus termos, era apenas para ressaltar a distância entre essas massas e o leitor erudito.

Por vinte anos, Perrault foi o parceiro mais próximo do ministro Colbert e, como tal, contribuiu para a implementação e o fortalecimento do poder real absoluto. Perrault estava encarregado do campo artístico: seu dever era criar estruturas para supervisionar e, assim, controlar os intelectuais. Ele criou Academias de pintura, escultura, música, arquitetura etc. Ao ser eleito para a Academia Francesa, em 1671, participou ativamente da criação do dicionário institucional, cujo objetivo era completar a ruína das variantes regionais e impor um modelo exemplar que diferenciasse o que era vulgar ou grosseiro daquilo que seria de bom gosto, outra maneira de controlar os escritores.

Perrault era um homem muito mais moderno do que seu mito permite acreditar, longe da imagem de bom burguês próximo às classes mais baixas. Ele participou ativamente da política e do trabalho literário de então e foi ambicioso e firme em suas posições. Foi o principal defensor da tendência modernista e considerou que o progresso só era possível através da fé católica; escreveu O Paralelo dos Antigos e dos Modernos sobre as Artes e as Ciências (Le Parallèle des Anciens et des Modernes en ce qui regarde les Arts et les Sciences), em quatro volumes, para defender sua teoria. Suas ambições eram políticas e, para afirmá-las, experimentou muitos estilos literários, inclusive o estilo galante. 
Charles Perrault publicou seus primeiros contos de fadas em 1694: A Paciência de Grisélidis, Os Desejos Ridículos e Pele de Asno, que foram publicados separadamente e depois reunidos em um livro. Em 1696, publicou A Bela Adormecida no Bosque, na revista Le Mercure galant, e seus demais oito contos em prosa no ano seguinte. Quando Perrault finalizou seus Contes, já havia perdido sua posição na Corte - Colbert morreu em 1683 - e passou a se dedicar a seus filhos. Somente a essa altura, escrever contos de fadas se tornou, ao mesmo tempo, uma forma de entretê-los (COLLINET, 1981) e de tentar retornar à corte seguindo o estilo dos salões, defendendo moralidades através de contos agradáveis. Para ele, aquele não era um trabalho relevante, opinião partilhada pelos seus contemporâneos (STORER, 1928).

\subsection{Um trabalho polimórfico}

Os Contes, no entanto, imediatamente tiveram um grande sucesso: oito reimpressões e duas imitações foram publicadas durante o período em que Perrault esteve vivo. Era um número impressionante, mesmo que a maioria dessas publicações fosse popular e barata. Deve-se mencionar que esse seu sucesso foi bastante incomum: os contos de fadas feitos nos salões não costumavam ser populares entre as classes mais baixas. Os contos de Perrault definitivamente pertencem ao gênero dos contos literários franceses, eles têm todas as suas características distintivas. Por outro lado, Perrault fez uso de narrativas populares sem operar modificações drásticas em sua estrutura, de modo que as pessoas reconheciam facilmente as histórias que conheciam tão bem. Estudos posteriores de folcloristas e historiadores da literatura mostraram que o livro de Perrault era, sem dúvida, baseado em uma coleção de contos tradicionais. Tem-se aí a preservação do folclore através do trabalho com temas populares, técnicas narrativas e fraseologia oral (SORIANO, 1975). No entanto, o vínculo com as narrativas populares não pode obliterar completamente a atitude condescendente do grande burguês em relação às classes mais baixas e suas tradições.

Temos agora uma visão geral mais apurada do trabalho de Perrault: é simultaneamente um compêndio de contos de fadas literários, feito à moda dos salões, uma 
paródia de contos populares e uma reescrita desses contos. É isso que torna seu trabalho único. Perrault retocou o estilo popular, manteve a estrutura das histórias e algumas frases típicas, mas ainda assim os apresentou em um estilo ao gosto dos intelectuais e aristocratas, fazendo uso de um vocabulário precioso e respeitando as regras de escrita dos contos de fadas de salão. No tocante às suas reais intenções, o debate ainda continua. O polimorfismo de seu trabalho provavelmente reflete o polimorfismo do homem.

\section{Processo de entrada no folclore}

\section{I. Os Iluminismos}

Luís XIV morreu em 1715, e com ele morreu um estilo de vida, todo um estado de espírito. Sua representatividade era tão forte que, quando faleceu, uma era terminou e uma outra teve início. Todas as realizações de seu reinado pareceram desatualizadas e os contos literários do preciosismo foram rapidamente esquecidos. A ruptura foi ainda mais profunda porque a maioria dos escritores de contos de fadas morreu ainda no início do século XVIII — Perrault morreu em 1703.

No século XVIII, o número de editoras havia aumentado drasticamente e o público leitor crescia rapidamente. Os contos, como um tipo de literatura facilmente acessível, também aumentaram sua audiência. Os Contes de ma Mère l'Oye, apesar de antiquados, ainda desfrutavam de enorme sucesso popular. Apenas quatro edições do livro foram mapeadas no século XVIII, muito provavelmente porque seu sucesso editorial deveu-se às edições simples, difíceis de serem contabilizadas. No entanto, esse tipo de publicação apresenta um problema, que é a despreocupação com a autoria: geralmente não se imprime exatamente o texto original. É o caso dos Contes, que passou por muitas modificações.

Após a morte de Luís XIV, muitos procedimentos foram questionados. A monarquia absoluta foi examinada, o debate religioso foi fortalecido e novos sistemas filosóficos nasceram. Esse contexto comprometeu o trabalho dos escritores do século 
XVIII. Embora na época tenha ocorrido uma abundante publicação de romances, a maior parte da produção literária estava relacionada ao debate filosófico e político. $\mathrm{O}$ espírito do século não favoreceu os contos de fadas; os Contes expressavam valores que estavam em total contradição com esse novo modo de ver o mundo. Perrault havia ajudado a reforçar o absolutismo real e defendeu a primazia da fé católica, que considerou como a principal fonte de progresso e modernismo. O progresso também foi um valor do Iluminismo, mas, para os filósofos, ele deveria ser baseado no raciocínio e no pensamento crítico. O reinado de Napoleão também não fora dos mais favoráveis aos contos de fadas. Embora o sucesso popular ainda fosse considerável, os contos de fadas, e principalmente os de Perrault, precisaram esperar por um novo reconhecimento da elite intelectual, o que se deu no Romantismo.

\subsection{Irmãos Grimm}

O século XIX viu surgir uma tendência muito mais duradoura que qualquer outra corrente literária, atingindo a maioria dos países europeus. Pode ocorrer como um arroubo democrático, ou como resultado de uma excitação dos sentimentos nacionais e patrióticos, ou mesmo ambos ao mesmo tempo. A tendência certamente foi generalizada, mas ocorreu mais cedo ou mais tarde de acordo com o país, com as condições econômicas e com as classes sociais envolvidas; pode ter consistido em debates teóricos ou insurgências sangrentas, com orientação liberal, conservadora ou revolucionária. Em todos os casos, descobriu-se que a cultura popular era digna de ser estudada, mesmo que nem todos os países partilhassem do mesmo entusiasmo. A Alemanha foi a iniciadora dessa tendência e os irmãos Grimm, suas figuras emblemáticas.

Tentando preservar o folclore nacional, eles coletaram histórias com um profundo respeito pela tradição. Conta-se que os Grimm não dispunham de antologias semelhantes já publicadas onde pudessem se inspirar quanto ao conteúdo de seus trabalhos. Assim, direcionando seus esforços para a tradição oral, eles teriam coletado mais de duzentos e cinquenta contos de informantes germânicos, que foram reescritos procurando manter o estilo dos narradores populares. Eles publicaram esse compên- 
dio, Contos Infantis e Domésticos (Kinder und Hausmaerchen), em 1812. No entanto, é interessante notar que nele foram incluídos todos os contos de Perrault. O caso de $A$ Bela Adormecida é bastante significativo. Trata-se, na verdade, de um conto literário, que não tem raízes tradicionais ou orais em país nenhum. No entanto, faz parte do livro dos Grimm.

O "mito de Perrault" já existia e seus contos eram considerados testemunhos folclóricos. Aliás, é bem verdade que Perrault está bem mais próximo do estilo popular do que a maioria de seus contemporâneos (BELMONT, 1986). Além disso, sabendo que a estrutura dos contos é praticamente a mesma em diferentes países europeus, com diferenças estilísticas que não distorcem a estrutura do gênero, não é ilógico que os Grimm tenham se inspirado no trabalho de Perrault para reproduzir contos que também existiriam em diferentes versões na tradição germânica.

\subsection{Romantismo e interesse no folclore}

O despertar nacional na França ocorreu de maneira diferente da Alemanha. A unidade nacional foi alcançada e as elites não tiveram que defender a independência territorial e as tradições nacionais contra um invasor estrangeiro, ao passo em que a Alemanha foi ocupada pela França entre 1807 e 1815 . Nesse sentido, o interesse pelas tradições nacionais na França era mais um tema literário do que uma demanda real.

A Revolução Industrial, o despovoamento do campo e o surgimento de uma numerosa classe trabalhadora que tardou a iniciar seus protestos: esses eram alguns dos motivos pelos quais o povo não podia mais ser ignorado. A democratização da leitura intensificou essa tendência e, finalmente, as elites literárias se interessaram pelas massas. A literatura se tornou dissidente, os intelectuais afirmavam estar do mesmo lado das pessoas pobres, exploradas e infelizes, enquanto, na verdade, tinham muito pouco contato com aqueles que defendiam. A tendência de refletir as aspirações populares levou naturalmente à reapreciação de textos folclóricos. Assim como o interesse pelas massas não era completamente genuíno, o interesse pelo folclore podia até ser real, mas ainda assim era superficial. Os contos de fadas de Perrault foram redescobertos, 
mas seu trabalho passou a ser analisado sob uma perspectiva sentimental, que desconsiderava sua real posição na história literária. "Descobriu-se" que Perrault não havia inventado seus contos de fadas do nada, pois teria se inspirado nas tradições orais e populares (WALCKENAER, 1876). E, imediatamente, o mito foi criado; Perrault passou a ser visto como um bom homem burguês que colecionava contos populares no campo e os reescrevia com absoluta fidelidade. Ele se tornou o símbolo, o precursor daqueles que queriam preservar a produção tradicional.

Naquela época, os Contes de Perrault atingiram o auge de sua popularidade. Eram histórias que as pessoas conheciam desde a infância e, portanto, tocavam-nas profundamente. Conscientes do que os leitores populares agora representavam em termos de dinheiro, as editoras começaram a lançar muitas edições do Contes em formatos e preços acessíveis às massas. Perrault adquiriu uma popularidade sem precedentes e, entre 1842 e 1913, houve pelo menos mais 233 edições de seus contos de fadas, por mais de sessenta editores diferentes. Isso significa uma média de três ou quatro publicações por ano, sem incluir as edições e traduções mais baratas. Os personagens de Perrault foram reapropriados pelo folclore popular e também penetraram nos círculos intelectuais. De forma semelhante, o Decadentismo os apropriou e modificou seu significado original (DE PALACIO, 1993). Essa tendência mostrou que Perrault ainda estaria muito presente no mundo da literatura e também que seus Contes haviam se tornado tão famosos que, mesmo que totalmente modificados, ainda eram reconhecidos pelo que haviam sido. Agora eles faziam parte da cultura comum.

\section{Conclusões}

No século 20, muitos especialistas em folclore analisaram o trabalho de Perrault com mais seriedade. Eles perceberam que, mesmo que o autor mantivesse a estrutura principal dos contos populares, seu trabalho não poderia ser considerado como um reflexo exato das narrativas populares da época. Historiadores da literatura encontraram origens literárias nos contos de Perrault. Os especialistas acreditam que autores italianos, principalmente Boccaccio e Straparola, podem tê-lo inspirado a escrever A Bela Ador- 
mecida, por exemplo (SORIANO, 1968). As principais origens escritas para os outros contos são provavelmente os livretos baratos da chamada Bibliotbèque Bleue francesa. Perrault os mencionava com desdém, mas sabe-se que ele de fato leu esses folhetos, como a maioria de seus contemporâneos. Após a publicação do livro de Perrault, a Bibliothèque Bleue também publicou seus contos, mas, na maioria dos casos, os textos não eram de autoria de Perrault. Eles foram modificados para se parecerem com os contos que as pessoas conheciam, embora ainda fossem apresentados sob o nome de Perrault; seus contos finalmente haviam retornado ao folclore tradicional. Até hoje, muitas publicações chamadas de "Contos de Perrault" são, na verdade, adaptações de algumas histórias direcionadas às crianças. Eles apenas mantêm a estrutura principal dos contos originais, como o próprio Perrault fez em relação às narrativas tradicionais. A influência que Perrault exerceu no folclore é comprovada pelo caso de A Bela Adormecida, conto de raízes literárias que passou a ser considerado narrativa tradicional. Através de Perrault, e mais tarde os irmãos Grimm, essa história se tornou parte da tradição popular.

Antes de instituir oficialmente o "folclore" local, os especialistas precisaram coletar material para o trabalho. A maior parte dessas coleções foi compilada na primeira metade do século XX na Europa em geral, e após a Segunda Guerra Mundial na França. A principal publicação dos folcloristas franceses é o Le Conte populaire français, catalog raisonné, de Delarue, continuado após a sua morte por Marie-Louise Tenèze (DELARUE, 1957; DELARUE; TENÈZE, 1964). Trata-se de uma enorme coleção de contos populares, e justamente a partir dessa coleção é que se levanta a questão principal a respeito da influência de Perrault: os contos coletados seriam os contos primitivos que inspiraram Perrault ou seriam versões modificadas dos contos estabelecidos por Perrault? Esse questionamento testifica, por si só, a profunda influência dos Contes no folclore. Agora é quase impossível determinar quais contos são os "originais" e quais são os escritos por Perrault. Apesar de os contos de fadas do autor terem sido distorcidos desde suas primeiras publicações, seu nome e a forma estrutural por ele estabelecida correspondem ao maior sucesso na história literária francesa. Nenhum outro livro passou por tantas modificações e, ainda assim, continuou a ser tão amplamente publicado e relido. 


\section{Referências}

BELMON, Nicole. Paroles Pä̈ennes. Paris: Imago, 1986.

COLLINET, Jean-Pierre. Introduction to the Contes de Perrault. Paris: Folio Gallimard, 1981.

DE PALACIO, Jean. Les Perversions du merveilleux. Paris: Séguier, 1993.

DE WALCKENAER, Charles Athanase. Lettres sur les contes de fées attribués à Perrault et sur l'origine de la féerie. Paris: Jouaust, 1826.

DELARUE, Paul. Le Conte populaire français, catalogue raisonné, Tome I. Paris: Érasme, 1957.

DELARUE, Paul; TENÈZE, Marie-Louise. Le Conte populaire français, catalogue raisonné,

tomes II \& III. Paris: Maisonneuve \& Larose, 1964.

GRIMM, Jacob and Wilhelm. Les Contes. Translation by Guerne, Armel. Paris: Flammarion, 1967.

PERRAULT, Charles. Contes. Genève: Slatkine Reprints, 1980.

ROBERT, Raymonde. Le Conte de fées littéraire en France de la fin du XVIIe à la fin $d u$ XVIIIe siècle. Nancy: Presses Universitaires de Nancy, 1982.

\section{Artigo originalmente publicado em:}

Trames - A Journal of the Humanities and Social Sciences. Academia Scientiarum 
Estoniae, 2007, vol. 11, n. 3, p. 276-283. ISSN: 1736-7514 (eletrônico); 1406-0922 (impresso).

Data da aprovação para tradução e publicação: 4 set. 2019.

Tradução de Paulo César Ribeiro Filho. 